И. Л. Дульчаева. Развитие графической компетенции школьников на уроках черчения в условиях дистанционного обучения

Научная статья

УДК 372.8:744

DOI: $10.18101 / 2307-3330-2021-1-45-50$

\title{
РАЗВИТИЕ ГРАФИЧЕСКОЙ КОМПЕТЕНЦИИ ШКОЛЬНИКОВ НА УРОКАХ ЧЕРЧЕНИЯ В УСЛОВИЯХ ДИСТАНЦИОННОГО ОБУЧЕНИЯ
}

\author{
(с) Дульчаева Ирина Львовна \\ кандидат педагогических наук, доцент, \\ Бурятский государственный университет имени Доржи Банзарова \\ 670000, Россия, г. Улан-Удэ, ул. Смолина 24a \\ dil71@mail.ru
}

\begin{abstract}
Аннотация. В данной статье рассматриваются сущность понятия «графическая компетенция», ее структура и критерии оценивания. Формирование графической компетенции у учащихся является актуальным направлением в связи с необходимостью приобщения подрастающего поколения к техническим специальностям. Графическая компетенция является составляющей инженерного мышления. В современных условиях дистанционного обучения большую сложность вызывает и развитие графической компетенции у учащихся на уроках черчения. Рассмотрены понятие «дистанционное обучение», инструменты дистанционного обучения, возможности развития графической компетенции учащихся при обучении черчению. В условиях дистанционного обучения повышается вероятность проблемы контроля образовательного процесса на расстоянии. Поэтому требуются специальные технические средства, приемы и методики, позволяющие решить эти проблемы. Приведены примеры обучения черчению учащихся с применением инструментов дистанционного обучения.
\end{abstract}

Ключевые слова: графическая компетенция, дистанционное обучение, обучение черчению

\section{Для цитирования}

Дульчаева И. Л. Развитие графической компетенции школьников на уроках черчения в условиях дистанционного обучения // Вестник Бурятского государственного университета. Образование. Личность. Общество. 2021. Вып. 1. С. 45-50.

Графическая компетенция учащихся является предметной компетенцией это способность и готовность применять знания, умения и навыки выполнения графических действий в условиях целостного образовательного процесса.

Графическая компетенция включает необходимые компоненты:

- графическая грамотность - умение читать с помощью графических средств, выполнять различную конструкторскую и техническую документации;

- графическая информация - это сведения, почерпнутые из различной технической и технологической литературы;

- графические знания - понятия о способах графического изображения изделий, процессов, явлений, о нормах и правилах в соответствии с системами стандартов; 
- $\quad$ графические умения - готовность человека оперировать пространственными образами, создаваемыми на различной графической основе, точно излагать свои и читать мысли другого человека по технической документации;

- $\quad$ графические навыки - владение приемами работы и программным инструментарием графических редакторов [1].

На основании структурного содержания графической компетенции учащихся целесообразно выявить следующие критерии формирования: когнитивноинформационный, операционно-деятельностный, когнитивно-креативный, мотивационно-личностный и оценочно-рефлексивный.

Для проверки графической компетенции учащихся нами проведены анкетирование, тестирование и анализ выполненных практических работ. В результате проверки одним из проблемных критериев у учеников был мотивационный. Учащиеся не совсем понимали необходимости изучения предмета, не было интереса к изучению черчения.

Для эффективного развития графической компетенции учащихся нами выбраны следующие педагогические условия:

- создание благоприятной и творческой атмосферы в процессе обучения, повышающей мотивацию к изучению предмета;

- предоставление учащимся выбора основных компонентов своего образования: смысла, темпа, форм и методов обучения;

- создание единого информационного пространства, обеспечивающего учащихся полной информацией о предмете, предоставляемой в интерактивном режиме [2].

При дистанционном обучении важным является повышение мотивации учащихся к изучению предмета. Для этого мы подбираем комплекс инструментов дистанционного обучения, привлекающих интерес к изучаемому предмету, проводим творческие олимпиады, конкурсы и др.

На рисунке 1 представлены виды деятельности обучающихся в дистанционном обучении. Инструментами дистанционного обучения нами выбраны платформа zoom и онлайн-доска Padlet. Дистанционный урок по черчению предполагает изучение теоретического материала и выполнение практических заданий. Теоретический курс проводился на платформе zoom. Мы выбрали еe в связи с возможностью во время представления теоретического материала школьникам демонстрации презентации по теме урока учителем и учениками и богатым потенциалом встроенной онлайн-доски, где учитель может дать задания ученикам и совместно с учениками выполнять практические работы. У онлайн-доски платформы zoom достаточно широкий набор инструментов, необходимых именно для урока черчения: построение точки, прямой, дуги, окружности и других геометрических фигур. 
И. Л. Дульчаева. Развитие графической компетенции школьников на уроках черчения в условиях дистанционного обучения

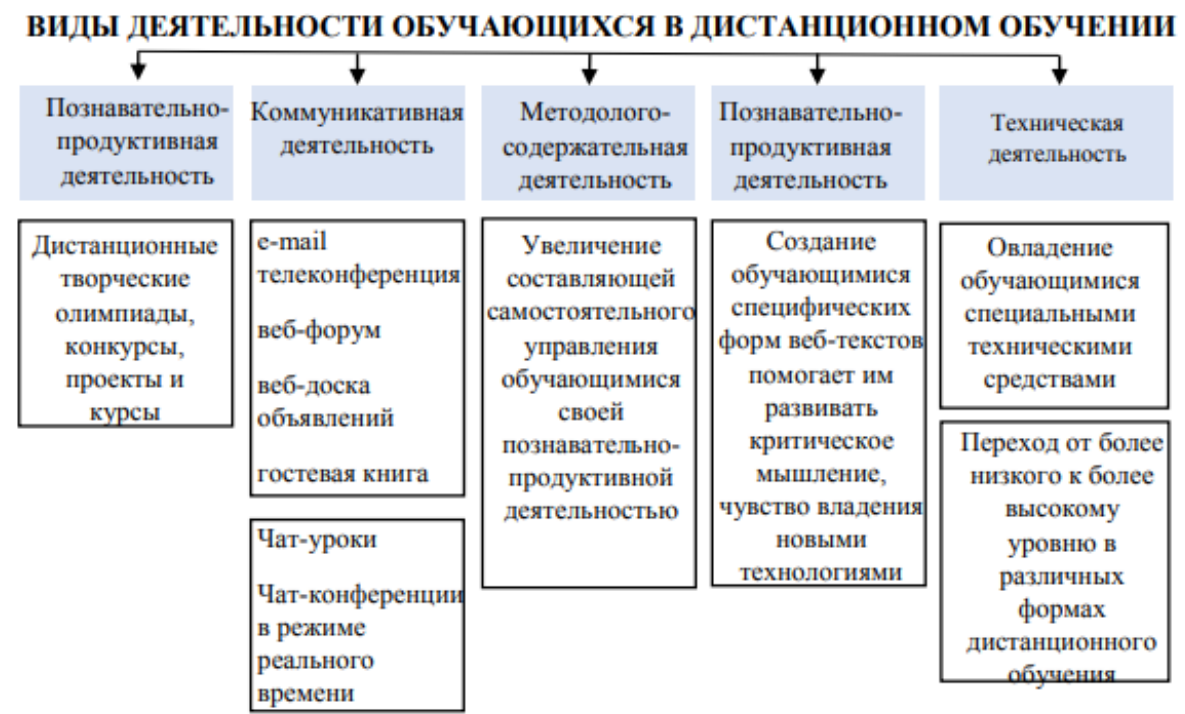

Рис. 1. Виды деятельности обучающихся в дистанционном обучении

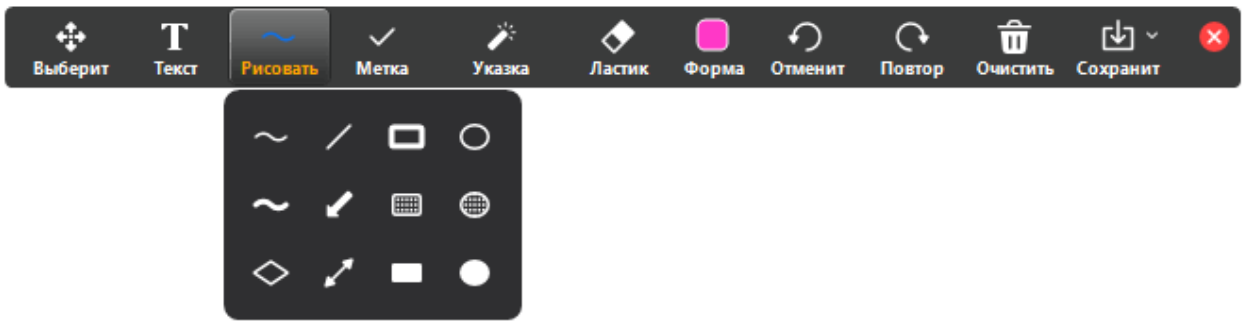

Рис. 2. Инструменты доски сообщений платформы zoom

Дополнительные теоретические и справочные материалы, задания для самостоятельной работы, задачи прикрепляются на онлайн-доске Padlet. Учащиеся знакомятся с подготовленным материалом, взаимодействуют друг с другом и с учителем с помощью «лайков», комментариев, добавления своих блоков и т. д. На первом этапе для повышения мотивации к изучению предмета учителю необходимо регулярное подтверждение конкретных работ в течение указанного в условиях времени, обеспечение обратной связи с обучающимися в течение оговоренного срока, обеспечение контроля за активностью обсуждения результатов взаимодействия, организация поддержки процесса отчетности учащихся, выявление тех, у кого технические затруднения при работе и при выполнении заданий, оказание помощи им.

Дистанционные занятия проходили при изучении темы «Аксонометрические проекции». При обучении для повышения уровня сформированности графической компетенции, особенно мотивационной составляющей, ученикам показыва- 
ли короткие видео для наглядного представления деталей. Показывали презентации и для закрепления полученных теоретических знаний, мы с учениками строили аксонометрические проекции на доске платформы ZOOM.

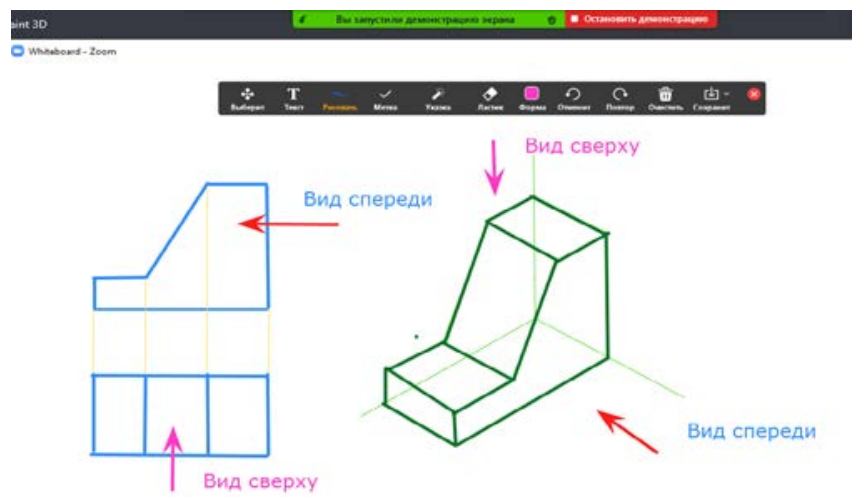

Рис. 3. Построение аксонометрии детали на платформе zoom

Использование возможностей платформы ZOOM дает хорошие представления ученикам. Можно строить различные геометрические фигуры, расставить размеры, показать стрелками, выделить определенные элементы различными цветами и другие. Очень важной составляющей является возможность совместного использования доски. Ученики также могут дочертить, сделать правки, выполнить задания на одной с учителем доске сообщений. Эти возможности повышают интерес у учащихся пробовать выполнять задания на доске, здесь нет такого страха, как стоя в классе у доски.
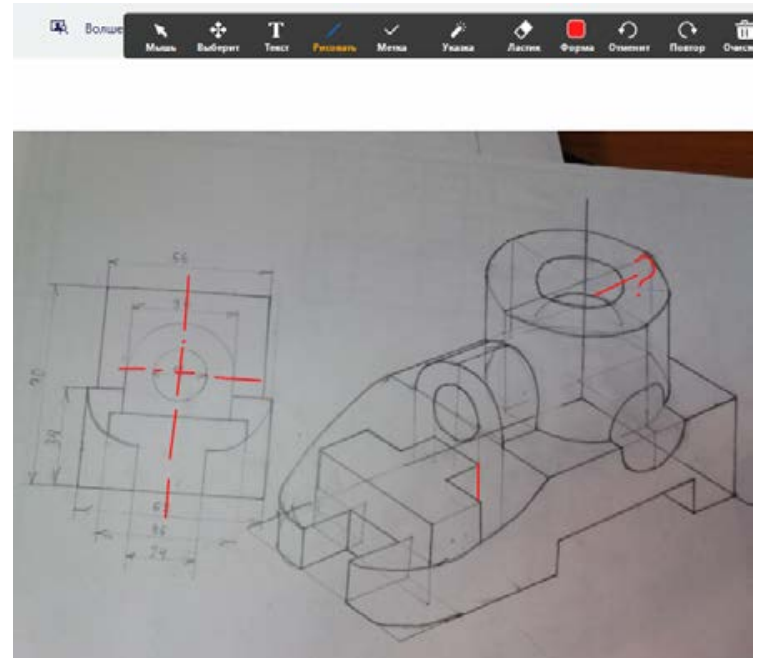

Рис. 4. Возможности редактирования на платформе zoom 
И. Л. Дульчаева. Развитие графической компетенции школьников на уроках черчения в условиях дистанционного обучения

На рисунке 4 показано, как можно с учениками на онлайн-доске платформы zoom совместно разобрать ошибки, показать неточности в выполнении заданий.

Решение домашних заданий школьники размещали на онлайн-доске Padlet. Эта виртуальная доска дает возможность каждому ученику разместить свою работу на доске, а преподавателю - прокомментировать и оценить каждого. Возможно также использование доски преподавателем для размещения учебнометодических, контрольно-измерительных и других материалов. Таким образом, на доске можно подать любой материал в электронной форме. После уроков мы на доске размещали видео, презентации и задания, чтобы ученики могли повторить при выполнении заданий. И также ученики домашние задания размещали там же, где учитель оставлял комментарии о правильности или неправильности выполненных заданий.

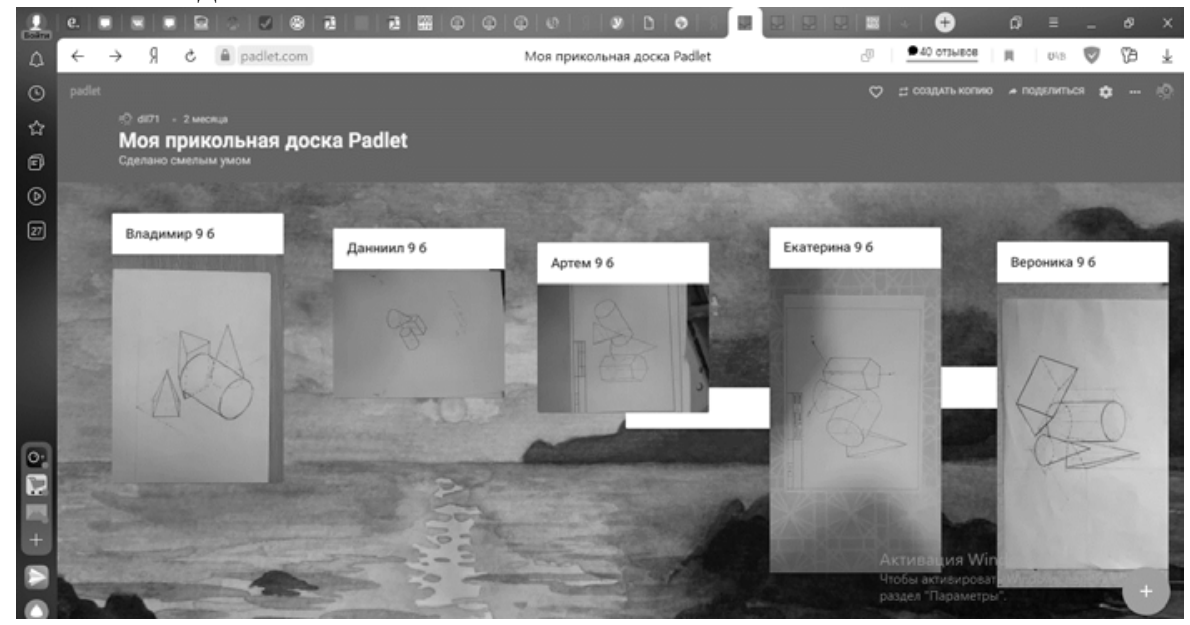

Рис. 5. Работы 9 б класса на онлайн-доске Padlet

На рисунке 5 представлена одна из страниц в Padlet с работами учащихся 9 б класса при изучении темы «Построение аксонометрии группы геометрических тел». Так, наглядно можно увидеть все работы, сравнить и оценить, а также учащиеся могут проанализировать неточности в своих работах и одноклассников.

В результате ученики с большим интересом работают на виртуальной доске, выполняют практические задания, работают в классе при выполнении практических заданий. Также и на платформе zoom ученики любят совместное использование доски, возможности поэтапного фотографирования выполнения работы, создания видеозаписи.

По результатам дистанционного обучения, выполненным работам мы можем сказать, что некоторые показатели графической компетенции улучшились, повысилась мотивация учащихся к изучению предмета.

Литература

1. Кармиджон Д. Оптимизация учебного процесса по формированию графических знаний и умений учащихся на уроках технологии // Ученые записки Худжандского университета им. Академика Б. Гафурова. 2017. URL: https://cyberleninka.ru/article/n/ optimizatsiya-uchebnogo- 
protsessa-po-formiravaniyu-graficheskih-znaniy-i-umeniy-uchaschihsya-na-urokah-trudovogoobucheniya-tehnologii (дата обращения: 24.03.2021). Текст: электронный.

2. Полат Е. С. Теория и практика дистанционного обучения: учебное пособие для студ. высш. пед. учебн. заведений / под ред. Е. С. Полат. Москва: Академия, 2004. 416 с.

3. Салахбеков А. П., Умаев А. У., Гамзаева М. В. Особенности формирования чертежнографических навыков на уроках технологии // Мир науки, культуры, образования. 2018. URL: https://cyberleninka.ru/article/n/osobennosti-formirovaniya-chertyozhno-graficheskih-navykov-naurokah-tehnologii (дата обращения: 24.03.2021). Текст: электронный.

4. Смородинова М. В. Особенности реализации педагогических условий в процессе формирования предметных компетенций учащихся // Педагогика сегодня: проблемы и решения: материалы III Международной научной конференции (г. Казань, март 2018 г.). Казань: Молодой ученый, 2018. C. 4-6. URL: https://moluch.ru/conf/ped/archive/276/13782/ (дата обращения: 24.03.2021). Текст: электронный.

Статья поступила в редакцию 02.03.2021; одобрена после рецензирования 25.03.2021; принята к публикации 09.04.2021.

\section{DEVELOPMENT OF GRAPHIC COMPETENCE IN SCHOOLCHILDREN AT THE LESSONS OF TECHNICAL DRAWING IN A CONTEXT OF DISTANCE LEARNING}

\section{Irina L. Dulchaeva}

Cand. Sci. (Education), A/Prof., Dorzhi Banzarov Buryat State University 24a Smolina St., Ulan-Ude 670000, Russia dil71@mail.ru

Abstract. The article discusses the concept of "graphic competence", its structure and estimation criteria. Development of graphic competence in schoolchildren is a hot topic, since there is a need to familiarize the younger generation with technical specialties. Graphic competence is a part of engineering thinking. But there are some difficulties in development of graphic competence in schoolchildren at the lessons of technical drawing in a context of distance learning. We have considered the concept of "distance learning", distance learning tools, opportunities for the development of graphic competence in schoolchildren at the lessons of technical drawing. In the conditions of distance learning the problem of monitoring the educational process at a distance increases. Therefore, special technical means and techniques are required to solve this problem. We have given the examples of teaching technical drawing to schoolchildren using distance learning tools.

Keywords: graphic competence; distance learning; teaching technical drawing.

\section{For citation}

Dulchaeva I. L. Development of Graphic Competence in Schoolchildren at the Lessons of Technical Drawing in a Context of Distance Learning. Education. Person. Society. 2021; 1: 45-50 (In Russ.).

The article was submitted 26.01.2021; approved after reviewing 25.01.2021; accepted for publication 09.04.2021. 